\title{
Correction to: Globalization, Human Capital Development, and Cultural Ecology
}

\author{
Amita Gupta and Guangyu Tan
}

\section{Correction to: \\ Chapter 1 in: G. Tan et al., Investment in Early \\ Childhood Education in a Globalized World, https://doi.org/10.1057/978-1-137-60041-7_1}

The original version of Chapter 1 was inadvertently published with incorrect contributors' names. "Gay Wilgus, Amita Gupta and Guangyu Tan" has now been changed to "Amita Gupta and Guangyu Tan". The chapter has been updated with the necessary change.

The updated version of this chapter can be found at https://doi.org/10.1057/978-1-137-60041-7_1

(C) The Author(s) 2020 